\title{
Dissimilar Welding of Austenitic and Martensitic Stainless Steel Joints for Nuclear Applications: a review
}

\author{
$S$. Sravan Sashank ${ }^{1}, S$. Rajakumar², R. Karthikeyan ${ }^{3}$ \\ ${ }^{1}$ Assistant Professor, Department of Mechanical Engineering, Gokaraju Rangaraju Institute of Engineering and Technology, Hyderabad, \\ Telangana 500090, India \\ ${ }^{2}$ Associate Professor, Department of Manufacturing Engineering, Annamalai University, Annamalai Nagar, Tamilnadu 608002, India \\ ${ }^{3}$ Professor, Department of Mechanical Engineering, Gokaraju Rangaraju Institute of Engineering and Technology, Hyderabad, Telangana \\ 500090, India
}

\begin{abstract}
Dissimilar Welding of Austenitic and Martensitic Stainless Steel Joints are commonly preferred in Nuclear Reactors where high temperature applications are needed. There has been a huge demand for materials which sustain corrosive environment with high rupture strength along with high temperature and pressure. These materials can be directly replaced with the traditional nickel based alloys to compensate for cost cutting and satisfy strength requirements. Dissimilar welding of these materials has been challenging due to the difference in its composition, properties and also heterogeneity in microstructure of these materials. A Study was done to identify what are the commonly used joining techniques, the mechanical properties of the joints and also the microstructure evolution of the dissimilar weld joints. This paper will emphasize on the work that was previously published in the area of dissimilar welding of these combinations of materials and also their challenges.
\end{abstract}

\section{Introduction}

There has been a lot of technological advancements that are taking place in the power industry. The demand for materials with good properties has drastically increased. Cost cutting for the materials has been one of the factor which is given upmost priority. Creep strength, corrosive resistance along with high temperature applications has bought lot of advancements in the materials. Nickel based alloys are quite commonly preferred but due to its high cost it can be replaced with creep strength enhanced ferritic/martensitic steels and austenitic stainless steels. The steam carrying pipes and headers, superheater, reheater tubes are one of the essential components. Steam headers are main piping which are operated at temperatures above $600^{\circ} \mathrm{C}$ and are subjected to thermal fatigue cracking during their service. Dissimilar Welding between ferritic/martensitic steels and Austenitic stainless steels is required in order to satisfy the strength requirements, cost cutting and service conditions [1]. The demand for materials with high temperature applications has grown significantly. Though Nickel based super alloys also have good creep strength and corrosion resistance at elevated temperatures, the strength requirements and cost cutting at those working temperatures can be replaced with creep enhanced ferritic/martensitic steels like P91, P92 and austenitic stainless steels like SS304, SS304H are preferred [1]. Joining of dissimilar materials is a challenging job due to the difference in thermal expansions of the materials and also since it is exposed to high temperature and high corrosive environments. Fig 1 shows the creep rupture strength of high temperature steels.

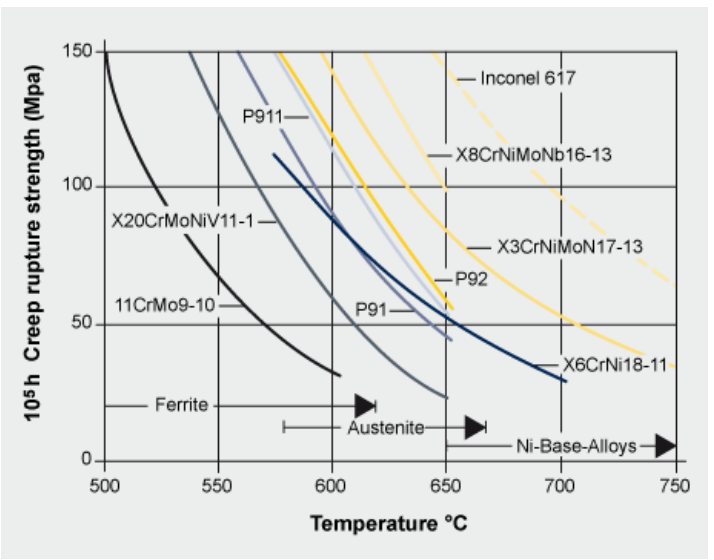

Fig 1: Creep Rupture Strength of High Temperature Steels

P91 ferritic/martensitic steel has an increasing demand for high temperature applications above $550{ }^{\circ} \mathrm{C}$ [2] and SS304 also possess good mechanical properties at high temperatures above $600{ }^{\circ} \mathrm{C}$ [3]. These materials when subjected to high temperatures do possess good creep rupture strength [4]. The materials are preferred for high temperature applications where some materials would succumb to creep. Creep plays a major role in the failure of the weld joints at high elevated temperatures [5]. For dissimilar joints at high temperatures, creep strength is one of the main characteristics. The joint

\footnotetext{
* Corresponding author: author@e-mail.org
} 
formed must be stronger or equal in strength to that of the weakest material. The review is emphasised on understanding the weldability, properties and microstructure characterization of the dissimilar joints of austenitic stainless steels and ferritic-martensitic steels.

Dissimilar joining has been challenging mainly due to the carbon migration and the formation of various phases. The strength and performance of these joints has been often weak and also the difference in the thermal expansions results in the creation of thermal stress due to which the joint might have a premature failure [6]. The steam generator connected with the heat exchanger is a combination where dissimilar joining of ferriticmartensitic steels and austenitic steels takes place, the steam generator for a dissimilar weld combination is shown in the Fig 2.

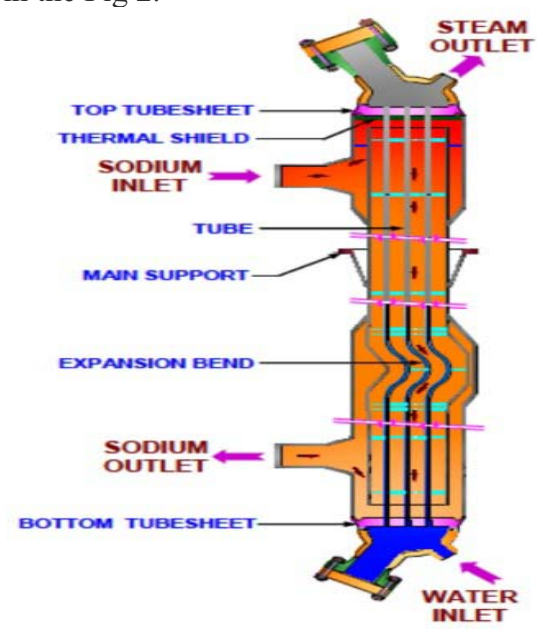

Fig 2: Steam Generator [7]

\section{Dissimilar Joining of Austenitic and Martensitic Stainless Steels}

To satisfy the strength and cost requirements, dissimilar joining of these combination of materials is mostly preferred. They can replace the nickel based super alloys which are mostly preferred for high temperature applications. Various fusion based welding techniques like GTAW, SMAW, SAW, LBW, EBW, PAW are used to join these combination of materials. TIG welding is one of the most versatile and commonly used process. It offers a great variety in increasing the productivity and also to produce sound quality welds. The welding process is selected based on the requirement, Laser Beam, Electron Beam and Plasma Arc processes have high arc densities, GTAW and GMAW processes have better deposition rates. The joints that are made must be capable of handling high temperatures, must have high strength, toughness and also must be capable of withstanding corrosive environments.

Most of the dissimilar welding combinations do require Preheating and Post Weld Heat Treatment. High Carbon Austenitic Grade Steels does not usually face the issue of cold cracking. Heating or welding of these materials at higher temperatures usually find a phenomena of carbide precipitation along the grain boundaries. The susceptibility of intergranular corrosion increases and sensitization is most likely to occur. This phenomena can be seen in high carbon containing austenitic steels rather than low carbon containing austenitic steels [8]

Dissimilar welding is a challenging due to the variation in chemical composition, physical and chemical properties and also coefficient of thermal expansions. This difference in the thermal expansions will cause and induce thermal stresses due to which the joints might fail at operating conditions. In dissimilar weld joint of austenitic grade stainless steels and martensitic steels, a HAZ formed towards the Austenitic side is thin as compared to the martensitic side due to the low thermal conductivity of the Austenitic stainless steels. Growing of the grains, formation of ferrites and precipitates will be increased. The finer grain structure will be replaced with the coarse grain structure. Post weld heat treatment is one of the solution which controls this phenomena and prevents the grain growth in HAZ. Austenitic grade steels generally are welded in hot rolled condition or in solution annealed condition, which controls the grain growth. The fast growing thermal cycle will lead to quick transformation of austenitic to ferritic phase which completely results in the formation of ferrites. Precipitates are also formed during this phenomena which are usually of carbides and nitrides. This phenomena will have a big effect on the corrosion behavior of the materials. Another key factor is the elemental composition of the base material and also the distribution of these precipitates along the grain boundaries. The corrosion resistance of the joint will be reduced due to this phenomena.

This variation causes a change in the microstructure most likely heterogeneous microstructure [9]. An unmixed zone will be created and this was mainly caused by the carbon migration from ferritic to austenitic steels. This would ultimately lead to the cracking of the joint near to the fusion zone. Hot cracking can be observed in the austenitic grade steels and cold cracking in the martensitic steel [10]. The basic problem is the dissimilar welding is to initially select an appropriate filler material. Different composition of the filler wires has to be used which will have an influence on the temperature of the base materials.

A study on joining SS 316 and P91 was made using Nickel based filler materials which helped in reducing the coefficient of thermal expansions between the two materials. Inconel 82 and Inconel 182 were majorly preferred for joining these materials. Most of the joining techniques involving these materials generate residual stresses.

In some ferritic steels like P91 and P92 the microstructural evolution and mechanical properties are one of the prime factors during the service conditions. Post weld heat treatment for these materials are recommended to enhance the mechanical properties across the HAZ and weld region which inturn helps to reduce the residual stresses which are generated during welding. PWHT is around $760^{\circ} \mathrm{C}$ and it helps in 
softening the martensitic structure [11]. PWHT provides good strength and adequate toughness to the HAZ. PWHT for austenitic region does not have much effect on its microstructure.

A study on the microstructure and mechanical behaviour of GTAW welded joint of ferritic/martensitic P91 and austenitic SS304L steel was done in both aswelded and post-weld heat treatment (PWHT) conditions, weld metal initially showed untampered martensite microstructure and after PWHT it was mainly characterized by tempered martensitic microstructure structure [12]. Through the study it was mainly found out to have the issues of carbon migration, metallurgical deterioration, mechanical property mismatch and also reduction in corrosion resistance and also has an increasing the tendency of stress corrosion cracking of the joint [13].

A study on A-TIG welding with wire feed was also done on martensitic-austenitic steel (P92 steel-304H ASS) dissimilar weld joints. The process resulted in the formation of austenitic microstructure by replacing the martensitic microstructure. It also showed a significant increase in ultimate tensile strength and impact toughness of the weld zone [14]. A similar kind of a study was done on P92 steel and SUS304 stainless steel using GTAW by using various groove shapes like V and $\mathrm{X}$ groove using a nickel based Alloy 82 filler wire Pre heating was initially done and the residual stresses were evaluated by hole drilling method. It was proven that the $\mathrm{X}$ groove joint showed superior mechanical properties that that of the V-groove type of the joint [15]. A study was also carried out on the effect of dynamic wire feeding on the dissimilar welding joints using GTAW process, dynamic wire feeding showed better symmetry and also good weld beads [16].

Joining of dissimilar 9\% Cr martensitic steel and austenitic stainless steel (ASS) is challenging there has been a drastic development of activated fluxes for improving the depth of penetrations in TIG welding processes. A-TIG welding is one of the process which is mostly employed to join $9 \% \mathrm{Cr}$ martensitic steel and austenitic stainless steel dissimilar combination but the main issue was that the fabricated components always produced poor properties like low ductility, poor hardness, poor impact toughness due to the phase transformation in the martensitic structure in the weld zone. PWHT is always recommended for these joints and it must be employed [17]. The challenge is selecting the conditions for PWHT, one way is to add a interlayers along the weld line so that the properties can be improved but the process is time consuming and complicated also. A study using A TIG welding with wire feed was performed which resulted in the formation of austenite microstructure, replacing the original martensite microstructure and it also improved the strength-ductility synergy with enhanced impact toughness also [18].

Dissimilar welding is preferred mostly for high temperature tubular applications and there had been lot of failures which were occurring due to the inferior properties for dissimilar welds of $\mathrm{Cr}$-Mo steels with austenitic stainless steels compared to that of the base metals, one main reason is the drastic difference between the thermal expansions of dissimilar metals of austenitic grade steels to ferritic steels and carbon migration from ferritic to austenitic steels. Most welding processes are being used using nickel based filler materials. A few innovative methods were adopted to have a transition in CTE in fusion welds. Autogeneous welds and also welds using filler materials can be performed for the combination of materials. A challenge will be identify the exact filler material to weld, and a material with coefficient of thermal expansion which lies between these two combination type of materials is most likely preferred and suggested. From the literature it was found out that Inconel is most preferred as filler material to weld Austenitic grade steels and Martensitic steels.

Solid-State welding processes are also preferred for joining dissimilar materials, friction welding does not involve melting and this significantly widens the choice of interlayer materials. Multiple interlayers can be easily employed and it also ensures a smooth and efficient way in changing the coefficient of thermal expansion between the base metals. Friction welding of modified 9Cr-1Mo steel (P91) and austenitic stainless steel AISI 304 was also attempted employing commercial nickelbased alloys like Inconel 600, Inconel 800 and Inconel 625 as interlayer materials which also proved to produce good creep strength, toughness and superior mechanical properties. Friction Stir Welding is also employed in joining these combination of materials, though very limited literature is available.

There has been lot on emphasis on the microstructure evolution and various studies on microstructure and mechanical properties were carried out by GTAW process on creep enhanced martensitic steels and austenitic steels. Most of the studies were carried out in as welded condition and also post weld heat treatment conditions. P91 with SS304L was joined by using P91 GTAW filler wire. After welding, PWHT has a major impact on mechanical properties of the welded joints of ferritic/martensitic steels and austenitic stainless steels [19].

\section{Metallurgy of Austenitic and Martensitic Stainless Steels}

The microstructures of martensitic steels are mostly characterized by tempered martensite decorated with precipitates. At higher temperature the coarsening will be accelerated and more stable structure will be formed which tends to lower down the creep strength of the material. Oxide participles are added into the martensitic steels, which tends to increase the temperature limit even though the original structure will be maintained intact and this also leads to the addition and production of oxide dispersion strengthened (ODS) martensitic/ferritic steels[12]. There is lot of emphasis on the microstructure evolution of martensitic/ferritic steels, that is why they play an important role in the area of power plants, nuclear reactors and other high temperature related applications. A detailed and comprehensive study was also done in the area of its application. Fig. 3 shows the 
microstructure and carbide precipitates of base metal P91 steel. The evolution of this along the grain boundaries can be clearly observed in the optical micrograph images. The micrographs also majorly show a typical lath morphology and the dissolution of these precipitates will lead to the formation of the coarse grain microstructure.
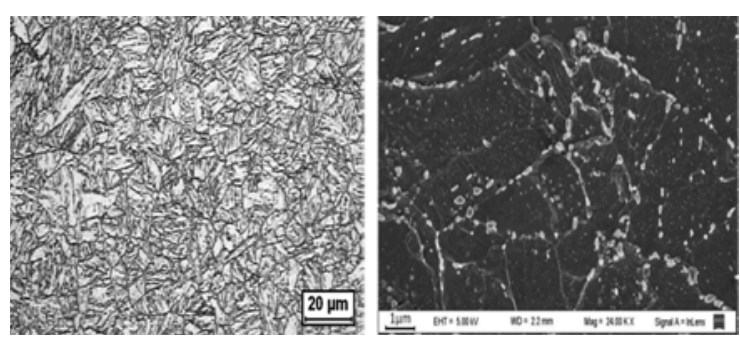

Fig 3: (a) Microstructure of Base Metal (b) Carbide Precipitation of P91 Steel [20]

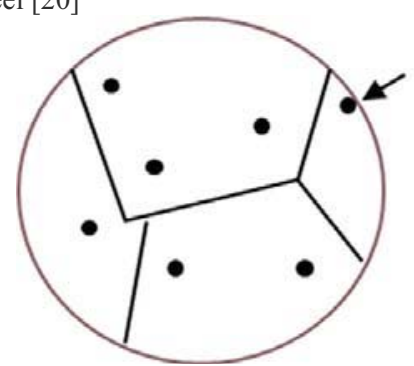

Fig 4: Carbide Precipitates after Normalizing and Tempering [21]

The microstructure of Austenitic Grade Steel SS304 base material is presented if Fig. 5 which consists of equiaxed austenitic grains. The precipitates are distributed within the austenite grains, which can provide good strength for SS304 at room temperature. It also has large equiaxed austenitic structure. There is also a large portion of columnar grains that exist. While the material is welded the grains of SS304 HAZ are not conductive enough to epitaxial growth. The microstructure of this weld metal is usually fully coarse austenitic which is mainly due to the high nickel content [22]

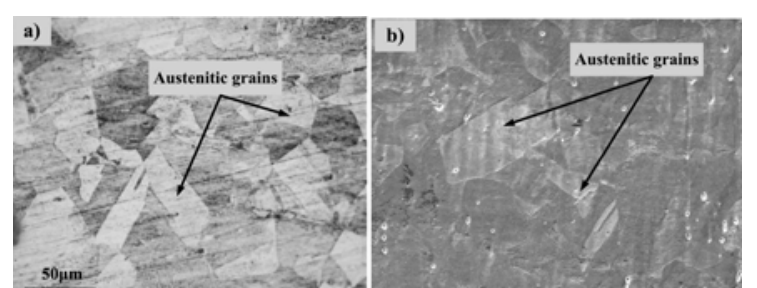

Fig 5: (a) Optical Micrograph of Base Metal (b) SEM Image of SS304 [19]

Another common grade of austenitic stainless steel is SS316. This material generally gets sensitized during
P91 ferritic-martensitic steel usually has an addition of $\mathrm{Nb}$ and $\mathrm{V}$ which has a major effect on the formation of carbides along with the major alloying element as chromium. The structure mainly is characterized by austenitic grains with martensitic laths formed inside it. Mxtype type of carbides are commonly present in this steel[14-15]. The carbides are mostly found at the prior austenitic grain boundaries, which helps in increasing the strength of the material by obstructing the dislocations. These carbides do get decomposed when exposed to high temperatures leading to the formation of $\mathrm{M}_{3} \mathrm{C}$ and laves phase. Carbide Precipitates of P91 ferritic-martensitic steel after Normalising and Tempering are shown in Fig. 4.

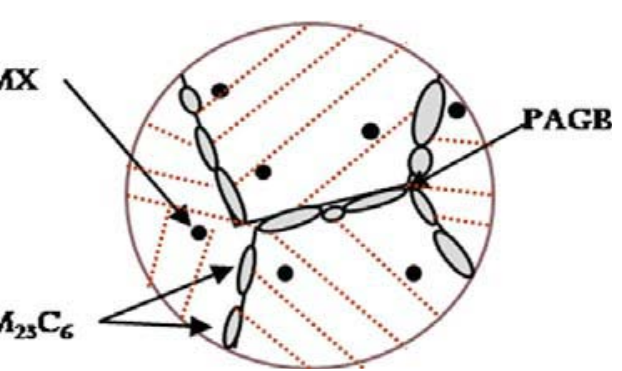

welding and it ca be overcome by decreasing the carbon content but this also has an effect on properties of the joints. The microstructure contains austenitic grains and also few carbides that precipitate along grain boundaries which can be shown in the Fig. 6 .
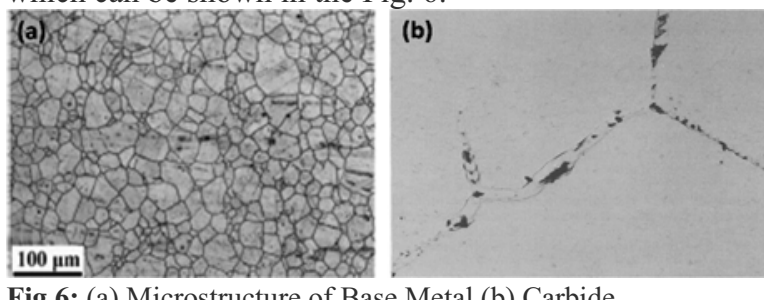

Fig 6: (a) Microstructure of Base Metal (b) Carbide

Precipitates of SS316 [19]

The carbide precipitation usually takes place over a prolonged amount of time and for varying temperatures also which is shown in the Fig. 7. The slow diffusion of chromium usually leads to this formation at the interface which results in the depletion at the boundaries which would also result in crack formation and decohesion of the metal due to shrinkages during the weld or while it is cooled. 


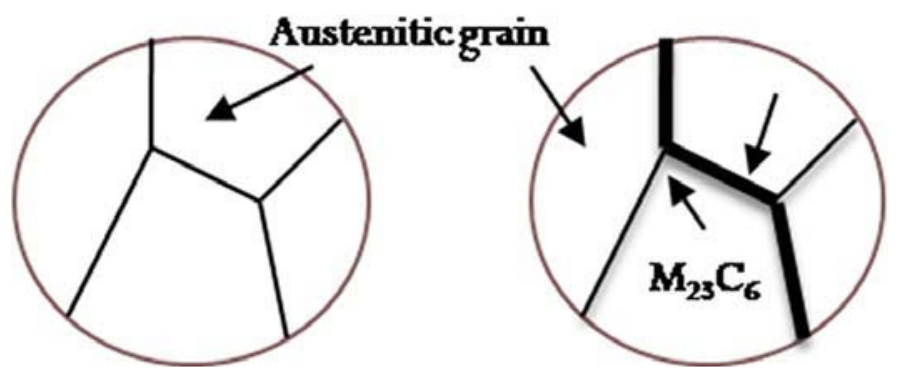

Fig 7: Carbide Precepitation along the grain boundaries [21]

A lot of work was carried out on the dissimilar joining of Austenitic and Martensitic Stainless steels and emphasis was done on identifying the weldability, microstructural development and mechanical characterization of the dissimilar weld joints. Most of the work was performend using Inconel filler materials or by using Ni-based filler materials which has a tendency of hot cracking [22]. Still there was only limited amount of work that was performed and there is a scope for much more research work to be done. Major work related to microstructure evolution in the various zones of the joints was still yet to be done. Residual stress formation and the crack behaviour was yet to be studied. Nickel based fillers are mostly suggested for dissimilar weld joints. Hot cracking and carbon migration is also one of the major issue due to the premature failure of the joint. Dissimilar joints also require post weld heat treatment and some of the major challenges can be overcomed. Some of the issues that are commonly faced during the dissimilar welding of austenitic and martensitic stainless steels has been clearly discussed, the weldability of the joints, its microstructure characterization have also been put forefront.

\section{Conclusions}

Dissimilar Welding of Austenitic and Martensitic Stainless Steels were discusses in this paper and the major aspects were focussed on the weldability, properties and Microstructure of the joints that were fabricated. The joints that were fabricated are capable enough to satisfy all the requirements of good heat resistance, good properties at elevated temperatures and excellent thermal conductivity along with creep and erosion. A lot of research work was carried out on this area with much more scope of work to be done for various applications. The study needs much more emphasis due to the challenges that are commonly faced mainly becuase of the heterogeneity in the microstructure. Detailed study is necessary to understand the failure of the joints during service. The study related to various welding processes or characterization for the joints will become helpful to understand about the joining of these materials. The quality of the weld will depend on various process parameters and the dissimilar weld joints are gaining lots of interest due to its advancements of new materials and its increased performance. The essential thing in this study is to understand about the service conditions and also the accuracy level of the joints that are fabricated. This study will help to have an understanding on the various combination of materials and also to explore for a wider range of applications in the future.

\section{References}

[1] Jayakumar, T., M. D. Mathew, and K. Laha. Procedia Engineering 55 (2013).

[2] Maridurai, T., M. S. Zameeruddin, and S. Biswas. Int. J. ChemTech Res 7, 2 (2014).

[3] Akram, Javed, Prasad Rao Kalvala, Mano Misra, and Indrajit Charit, Materials Science and Engineering: A 688 (2017).

[4] Durul Ulutan, Tugrul Ozel, International Journal of Machine Tools \& Manufacture 51 (2011).

[5] Li, Yongkui, Hiromichi Hongo, Masaaki Tabuchi, Yukio Takahashi, and Yoshio Monma, International journal of pressure vessels and piping 86, 9 (2009).

[6] Kumar, Prabhat, and Aravinda Pai., Procedia Engineering 86 (2014).

[7] Chetal, S. C., P. Chellapandi, P. Puthiyavinayagam, S. Raghupathy, V. Balasubramaniyan, P. Selvaraj, P. Mohanakrishnan, and Baldev Raj., Energy Procedia 7 (2011).

[8] Siefert, J. A., and S. A. David, Science and Technology of Welding and Joining 19, 4 (2014).

[9] Zhao, Y., et al. Materials at High Temperatures 32, 6 (2015).

[10] Vekeman J, Huysmans S, De Bruycker E., ASM International (2012).

[11] Sawada, K., Hara, T., Tabuchi, M., Kimura, K., \& Kubushiro, K., Materials Characterization, 101 (2015).

[12] Thakare, J. G., Pandey, C., Gupta, A., Taraphdar, P. K., \& Mahapatra, M. M., Fusion Engineering and Design, 168 (2021).

[13] Jang, C., Lee, J., Kim, J. S., \& Jin, T. E., International Journal of Pressure Vessels and Piping, 85, 9 (2008).

[14] Sharma, P., \& Dwivedi, D. K., Materials Letters, 285 (2021).

[15] Li, Suo, Long Hu, Peiyuan Dai, Tao Bi, and Dean Deng, Journal of Manufacturing Processes, 66 (2021).

[16] e Silva, Régis Henrique Gonçalves, Kauê Correa Riffel, Marcelo Pompermaier Okuyama, and Giovani

\footnotetext{
* Corresponding author: author@e-mail.org
} 
Dalpiaz, Journal of Materials Processing Technology, 269 (2019).

[17] Liu, Kaiyue, Dongpo Wang, Caiyan Deng, Baoming Gong, and Shipin $\mathrm{Wu}$, Materials Science and Engineering: A 770 (2020).

[18] Sharma, Pratishtha, and Dheerendra Kumar Dwivedi, Materials Letters, 285 (2021)

[19] Mahajan, Sumit, and Rahul Chhibber, Materials and Manufacturing Processes, 35, 9 (2020).

[20] Xu, D. M., G. Q. Li, X. L. Wan, R. D. K. Misra, X. G. Zhang, G. Xu, and K. M. Wu, Materials Science and Engineering: A 720 (2018).

[21] Awale, Deepshree D., Atul R. Ballal, and Manjusha M. Thawre, Materials Today: Proceedings, 28 (2020).

[22] Liang, Zhiyuan, Qinxin Zhao, Jianguo Deng, and Yungang Wang, Materials at High Temperatures, 35, 4 (2018). 